\title{
Histological composition and progression of carotid plaque
}

\author{
Liz Andréa Villela Baroncini*1, Antonio Pazin Filho1, \\ Simone Gusmão Ramos ${ }^{2}$, Antonio Roberto Martins ${ }^{3}$ and \\ Luiz Otavio Murta Jr ${ }^{4}$
}

\begin{abstract}
Address: ${ }^{1}$ Department of Internal Medicine, Faculdade de Medicina de Ribeirão Preto, University of São Paulo, São Paulo, Brazil, ${ }^{2}$ Department of Pathology, Faculdade de Medicina de Ribeirão Preto, University of São Paulo, São Paulo, Brazil, ${ }^{3}$ Department of Pharmacology, Faculdade de Medicina de Ribeirão Preto, University of São Paulo, São Paulo, Brazil and ${ }^{4}$ Department of Physics and Math, Faculdade de Filosofia, Ciências e Letras de Ribeirão Preto, University of São Paulo, São Paulo, Brazil

Email: Liz Andréa Villela Baroncini* - lizandreabaroncini@hotmail.com; Antonio Pazin Filho - apazin@fmrp.usp.br; Simone Gusmão Ramos - sgramos@fmrp.usp.br; Antonio Roberto Martins - armartin@fmrp.usp.br; Luiz Otavio Murta - murta@fclrp.usp.br

* Corresponding author
\end{abstract}

Published: 26 February 2007

Thrombosis Journal 2007, 5:4 doi:10.1 186/1477-9560-5-4
Received: 6 December 2006

Accepted: 26 February 2007

This article is available from: http://www.thrombosisjournal.com/content/5/l/4

(C) 2007 Baroncini et al; licensee BioMed Central Ltd.

This is an Open Access article distributed under the terms of the Creative Commons Attribution License (http://creativecommons.org/licenses/by/2.0), which permits unrestricted use, distribution, and reproduction in any medium, provided the original work is properly cited.

\begin{abstract}
Background: To analyse histological composition and progression of carotid plaque.

Methods: Thirty-one patients ( 22 males, mean age $68.03 \pm 7.3$ years) admitted for carotid endarterectomy for extracranial high-grade internal carotid artery stenosis $(\geq 70 \%$ luminal narrowing) were enrolled. The patients were divided into 2 groups according to symptomatology (group I, I 7 symptomatic patients; and group II, I 4 asymptomatic patients). A histological analysis and inflammatory cell quantification of each excised carotid plaque was made. Nine carotid arteries were removed from human cadavers that were not preselected for carotid artery disease. These specimens were used as a control tissue without any macroscopic signs of atherosclerotic plaques.
\end{abstract}

Results: Fifty eight percent of all carotid plaques were classified as complex plaque with possible surface defect, hemorrhage or thrombus. The inflammatory cells concentration did not differ between the two groups. All specimens from human cadavers were classified as preatheroma with extracellular lipid pools.

Conclusion: Asymptomatic and symptomatic patients could have the same histological components on their carotid plaques. Fibrotic and calcific plaques could become vulnerable as complex plaques with surface defect, hemorrhage and thrombus could remain silent. Asymptomatic carotid stenosis should be followed close with no invasive diagnostic methods and clinical evaluation.

\section{Background}

In 1995, a report from the Committee on Vascular Lesions of the Council on Atherosclerosis, American Heart Association (AHA), had described the characteristic components and pathogenic mechanisms of the various advanced atherosclerotic lesions [1]. This report provides a classification of human atherosclerotic lesions based on their histological composition and structure and reflects the temporal natural history of disease. The lesions were classified by Roman numerals that indicate the usual 
sequence of lesion progression, grading from type I (initial lesions) to type VIII (fibrotic plaque). Varying proportions of different components (connective tissue extracellular matrix; crystalline cholesterol, cholesteryl esters, phospholipids; and cells such as monocyte-derived macrophages, T lymphocytes, and smooth muscle cells) occur in different plaques, thus giving rise to a spectrum of lesions [2,3]. Surface defects, hematoma, and thrombotic deposits futher damage, deform, and thicken, and accelerate conversion from clinically silent to overt disease [1]. The present study was designed to characterize the progression and composition of carotid plaque, according with patient symptomatology, based on the American Heart Association (AHA) classification for human atherosclerotic lesions $[1,4]$. The inflammatory cell quantification was based on estereology method.

\section{Methods}

\section{A. Patients}

Thirty-six nonconsecutive surgical inpatients admitted for carotid endarterectomy for extracranial high-grade $(\geq$ $70 \%$ ) internal carotid artery stenosis were entered into this study between February 2003 and July 2005 from 3 participating hospitals. Local ethical committee approval was obtained for the study and procurement of specimens. Written informed consent was obtained from all patients. Exclusion criteria were: a disorder that could seriously complicate surgery (3 patients); terminal cancer ( 1 patient); and patient refusal of operation (1 patient). The study was conducted on 31 common or internal carotid artery plaques from the 31 remaining patients (22 men and 9 women; mean age $68.03 \pm 7.3$ years). A clinical examination, including neurological exam, with particular care taken to establish the number and duration of ischemic events, and a record of the time from the last symptom and the operation, was obtained from each patient. Before surgery, all patients underwent a: 1 - either cerebral angiography or magnetic resonance angiography and Duplex ultrasound for grading carotid artery stenosis and assessment of intracranial arterial system; and 2 either computer tomography (CT) or magnetic resonance brain scan. The presence or absence of infarction in the corresponding middle cerebral artery territory was noted. Focal cerebral ischemic events were defined as transient ischemic attack (TIA), amaurosis fugax (AF), central retinal artery occlusion (CRAO), or cerebrovascular accident. Patients were considered to be symptomatic if they had experienced AF, TIA or stroke ipsilateral to the carotid lesion being studied. Silent infarcts and lacunar symptomatology, diagnosed by a neurologist based on clinical and brain computer tomography (CT) scan and/or magnetic resonance imaging (MRI) located ipsilateral to the stenosis, were also considered symptomatic. On the other hand, patients without any history of recent neurologic symptoms or with nonspecific, nonhemispheric symptoms such as dizziness and vertigo were considered asymptomatic. Each patient was then assigned preoperatively to 1 of 2 groups on the basis of their symptom: group I ( $\mathrm{n}=17$; mean age $66 \pm 7$ years) symptomatic patients; and group II ( $\mathrm{n}=14$; mean age $67.6 \pm 6.81$ years $)$ consisting of all asymptomatic patients. At the baseline examination, measurements of height, weight, body mass index, blood pressure, fasting serum total cholesterol, HDL cholesterol, LDL cholesterol, triglycerides, fasting plasma glucose, electrocardiograms and information about coronary artery disease, diabetes mellitus and smoking habits was collected. Percentages of carotid diameter reduction, procedural methods, concomitant therapy, age, sex, and risk factors did not differ between the 2 groups (Table 1 ). Nine carotid arteries were removed from human adult cadavers that were not preselected for carotid artery disease. These specimens were used as a control tissue without any macroscopic signs of atherosclerotic plaques.

Table I: Patient's Characteristics

\begin{tabular}{|c|c|c|}
\hline & Group I ( $\mathrm{n}=17)$ (symptomatic) & Group II ( $n=14)$ (asymptomatic) \\
\hline Age, years & $66.6 \pm 6.7$ & $67.6 \pm 6.81$ \\
\hline Sex, M/F & $12 / 5$ & $9 / 5$ \\
\hline Hypertension & 12 & 13 \\
\hline Diabetes mellitus & 6 & 3 \\
\hline Active Smoking & 5 & 4 \\
\hline Hypercholesterolemia & 4 & 3 \\
\hline CAD & 4 & 4 \\
\hline Aspirin & 17 & 14 \\
\hline Statin & 6 & 5 \\
\hline ACE inhibitors & 10 & 10 \\
\hline Ticlopidine & 4 & 1 \\
\hline
\end{tabular}

$C A D=$ coronary artery disease 
Table 2: American Heart Association Classification for human atherosclerotic lesions according clinical groups.

\begin{tabular}{lcc}
\hline & Group I $(\mathrm{n}=17)$ (symptomatic) & Group II ( $=$ I4) (asymptomatic) \\
\hline Type IV & 2 & 0 \\
Type V & 4 & 2 \\
Type VI & 7 & 11 \\
Type VII & 2 & 0 \\
Type VIII & 2 & 1 \\
Inflammatory cells & $0-109$ & $0-88$ \\
(minimum - maximum/specimen - median \pm sd) & $(22 \pm 28)$ & $(26 \pm 29)$
\end{tabular}

\section{B. Procurement of tissue specimens and histological analysis}

Carotid plaques were obtained immediately after endarterectomy. All surgeries were performed with standard surgical techniques, and with minimal manipulation of the specimen. No attempts were made to evaluate the presence and the degree of surface ulceration or thrombus. The plaque should be removed in bloc, without fragmentation or significant distortion. After removal, the section of plaque for histological analysis was placed in fresh $4 \%$ paraformaldehyde solution and partly decalcified overnight, in order to be sectioned subsequently. The samples were transected transversely at 3 to $4 \mathrm{~mm}$, and embedded in paraffin. For the most of the specimens, five to six blocks were avaiable. Histological analysis was performed by an experience pathologist (SGR), based on American Heart Association classification for human atherosclerotic lesions $[3,4]$. The inflammatory cell quantification was assessed by light microscopy with final magnification of $400 \times$, using an ocular lens with a grid graticule. The observer selected a region in the plaque section with as many inflammatory cells as possible (hot spot). When no inflammatory area was clearly identified the selection was made in an aleatory way. Total area examined was $0.6 \mathrm{~mm}^{2}$ and each graticule grid corresponds to an area of $0,0625 \mathrm{~mm}^{2}$ with magnification of
$400 \times$. The inflammatory cells were counted in 10 different graticule area in each specimen. The human carotid arteries removed from cadavers had received the same histological treatment.

\section{Statistical analysis}

Continuous variables were expressed as mean \pm SD. Statistical significance was indicated by a value of $P<0.05$. The comparison of the histological parameters among the groups was done by non-parametric test of Kruskal-Wallis.

\section{Results}

The histological analysis according to AHA classification for human atherosclerotic lesions is disposed in Table 2. Fifty eight percent of all carotid plaques were classified as Type VI of AHA. All the carotid arteries removed from human cadavers were classified as Type III (preatheroma with extracellular lipid pools). The inflammatory cells counting did not differ between the groups and between the plaque types, varying from 0 to 109 cells by specimen. Figures 1 and 2 are examples of types III, IV, V, VI, VII and VIII of AHA classification.

\section{Discussion}

An asymptomatic patient with carotid artery stenosis is always a reason of concern for his personal physician.
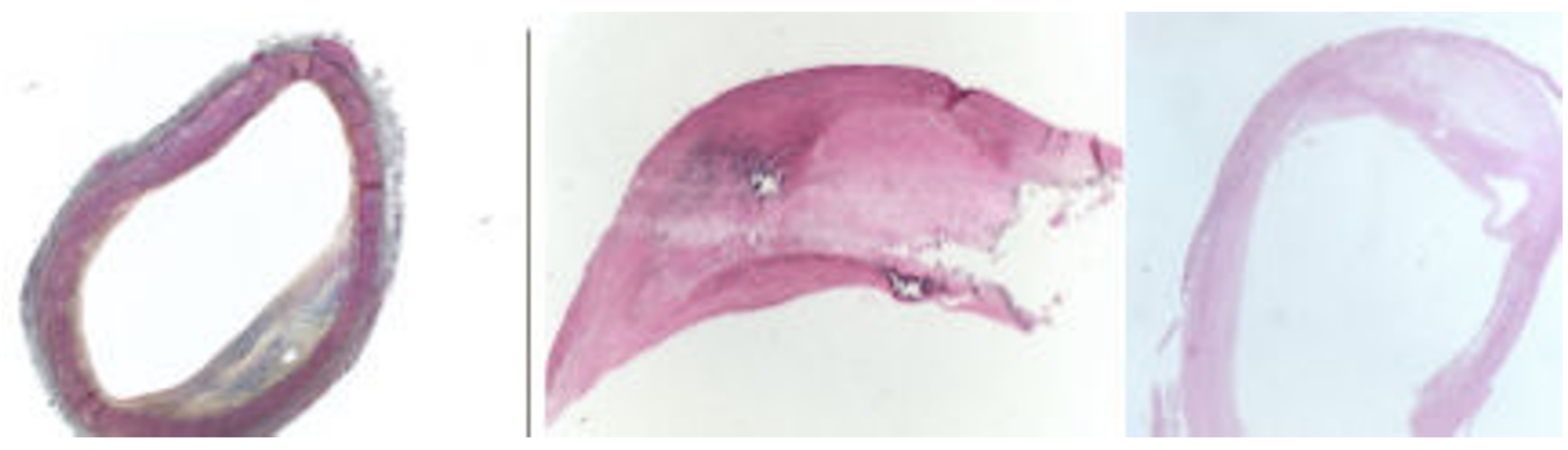

Figure I

Left panel: Cadaver carotid artery. Type III AHA. Preatheroma with extracellular lipid pools (blue area in the center). Mid panel: Type IV AHA. Atheroma with confluent extracellular lipid core (pink area in the center). Right panel: Type V AHA. Fibroatheroma (clearer pink area - atheroma - surrounded by darker pink area - fibrosis). 

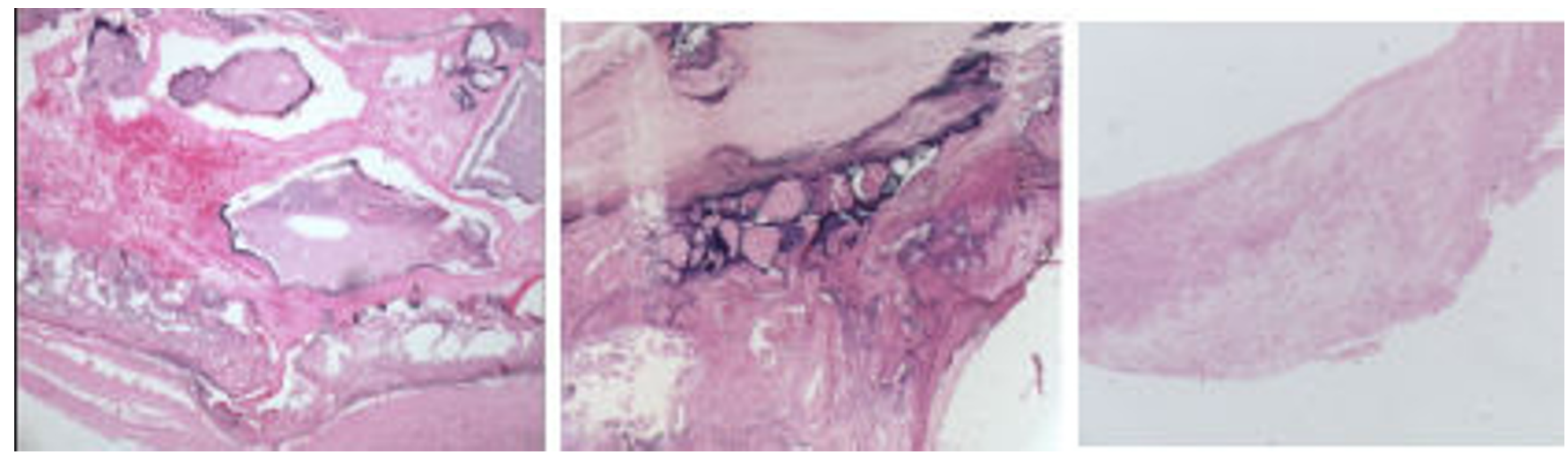

\section{Figure 2}

Left panel: Type VI AHA. Complex plaque with possible surface defect, hemorrhage (dotted red area) or thrombus near the lipid core (in the center). Mid panel: Type VII AHA. Calcified plaque (purple areas). Right panel: Type VIII AHA. Fibrotic plaque without lipid core (extensive area of fibrosis).

Current AHA guidelines recommended carotid endarterectomy (CEA) for asymptomatic patients, for stenosis $60 \%$ to $99 \%$, if the risk of perioperative stroke or death is less than $3 \%$. However, factors in addition to the degree of stenosis, such as the histological composition of the plaque, may be responsible for the determination of stroke risk. The mature atherosclerotic plaque is a complex structure suffering constantly of reparative process and its histological characterization is not easy. It was expected that types IV (atheroma with confluent extracellular lipid core), V (fibroatheroma) and VI (complex plaque with possible surface defect, hemorrhage or thrombus) of AHA classification should be the only ones found in group I (symptomatic patients), but we had classified two patients as having type VII (calcified plaque), and two patients as type VIII (fibrotic plaque). Also, in group II (asymptomatic patients) we found 11 patient as having plaques type VI. The fact that all surgical specimens in the present study had a high grade of complexity shows the challenge to try to separate vulnerable from stable carotid plaques. In the early stages of atherosclerosis the sequence is predictable, characteristics, and uniform, as we could evidence in the carotid arteries removed from human cadavers. However, lesions may subsequently progress in different morphogenetic sequences, resulting in several characteristic lesion types and clinical syndromes [1]. It is well known that vulnerable plaques contain more total lipid and cholesterol, and less collagen and calcium as we could demonstrate in previous study [5-8]. However, the present study had evidenced that the atherosclerotic plaque is not a one-way progression from a "soft" to a "hard" plaque. When or why some these plaques will cross the line between stable to vulnerable? We know that fissures can occur in fibrotic and calcific plaques making then more vulnerable and the present study had evidenced that inflammatory cells are a con- stant part of atherosclerotic process, even in asymptomatic patients. The answer probably will be in the imunohistochemical analysis [9-14]. Most we have learned about vulnerable plaques is from imaging methods (ultrasound, magnetic resonance, and tomography) that wants to predict vascular events [15-29]. All these methods are able to identify precisely different proportions of fibrous tissue, lipid tissue and calcium as we had demonstrated in previous study [5]. Some methods, mainly ultrasound tissue characterization can classify heterogeneous tissues based on second order statiscal parameters (entropy, homogeneity and energy) but they are failed in determine what this heterogeneous finds really means. Are they related with intrinsic reparative process inside the plaques? All these considerations suggest that asymptomatic carotid stenosis should be followed close with no invasive diagnostic methods and clinical evaluation.

\section{Study limitations}

First, the small number of patients was an important study limitation. This limitation will not be easily overcome, since the improvement of carotid artery stenting techniques will make histological analysis of carotid plaques an infrequent procedure. Second, by necessity, the plaques were sectioned and only a small proportion of each plaque was examined microscopically, and it may well be that features were missed in some patients. Most large lesions vary in composition along their length. This may particularly apply to the classification of fibrotic and calcific plaques in group I, where probably different components were missed when a small number of individual sections were examined. Third, we considered in this study patients with lacunar infarctions (LI) as had symptomatic carotid plaques. According to Tejeda et al [8], although significant carotid stenosis was observed at 
lower levels in LI, its pathogenic value should be taken into account because, when detected on the symptomatic side, it is not only a marker of atheromatosis but also a process potentially linked to LI. And finally, we did not perform imunohistochemical analysis in the present study that would certainly differentiate more instable carotid plaques, with large macrophage infiltration.

\section{Conclusion}

Mature carotid plaques are complex structures and their histological classification is a real challenge. Asymptomatic and symptomatic patients could have the same histological components on their carotid plaques. Fibrotic and calcific plaques could become vulnerable as complex plaques with surface defect, hemorrhage and thrombus could remain silent. Asymptomatic carotid stenosis should be followed close with no invasive diagnostic methods and clinical evaluation.

\section{Competing interests}

The author(s) declare that they have no competing interests.

\section{Authors' contributions \\ LAVB designed the study.}

APF also designed the study and made the statistical analysis.

LOMJ also designed the study.

ARM oriented in the histologic analysis of the plaques.

SGR made the histological examination of the carotid plaques.

All authors read and approved the final manuscript.

\section{References}

I. Stary HC, Chandler AB, Dinsmore RE, Fuster V, Glagov S, Insull W, Rosenfeld ME, Schwartz C], Wagner WD, Wissler RW: A definition of advanced types of atherosclerotic lesions and a histological classification of atherosclerosis. Arterioscler Thromb Vasc Biol 1995, I5:1512-1531.

2. Fayad ZA, Fuster V: Clinical imaging of the high-risk or vulnerable atherosclerotic plaque. Circ Res 200I, 89:305-16.

3. Crisby M, Nordin-Fredriksson G, Shah PK, Yano J, Zhu J, Nilsson J: Pravastatin treatment increases collagen content and decreases lipid content, inflammation, metalloproteinases, and cell death in human carotid plaques. Implications for plaque stabilization. Circulation 200I, I 03:926-933.

4. Cai JM, Hatsukami TS, Ferguson MS, Small R, Polissar NL, Yuan C: Classification of human carotid atherosclerotic lesions with in vivo multicontrast magnetic resonance imaging. Circulation 2002, 106:1368-1373.

5. Baroncini LAV, Pazin Filho A, Murta Junior LO, Martins AR, Ramos SG, Cherri J, Piccinato CE: Ultrasonic tissue characteriztion of vulnerable carotid plaque: correlation between videodensitometric method and histological examination. Cardiovascular Ultrasound 2006, 4:32.

6. Wilhjelm JE, Grønholdt MLM, Wiebe B, Jespersen SK, Hansen LK, Sillesen H: Quantitative analysis of ultrasound B-mode imag- esof carotid atherosclerotic plaque: correlation with visual classification and histological examination. IEEE Trans Med Imag 1998, 17:910-922.

7. Takiuchi S, Rakugi H, Honda K, Masuyama T, Hirata N, Ito H, Sugimoto K, Yanagitani Y, Moriguchi K, Okamura A, Higaki J, Ogihara T: Quantitative ultrasonic tissue characterization can identify high-risk atherosclerotic alteration in human carotid arteries. Circulation 2000, 102:766-770.

8. Tejada J, Díez-Tejedor E, Hernández-Echebarría L, Balboa O: Does a relationship exist between carotid stenosis and lacunar infarction? Stroke 2003, 34:|404-I4II.

9. Cipollone F, Prontera C, Pini B, Marini M, Fazia M, De Cesare D, lezzi A, Ucchino S, Boccoli G, Saba V, Chiarelli F, Cuccurullo F, Mezzetti A: Overexpression of functionally coupledcyclooxygenase-2 and prostaglandin $E$ synthase in symptomaticatherosclerotic plaques as a basis of prostaglandin $E(2)$-dependent plaque instability. Circulation 2001, I04:92I-27.

10. Loftus IM, Naylor AR, Goodall S, Crowther M, Jones L, Bell PRF, Thompson MM: Increased Matrix Metalloproteinase-9 activity in unstable carotid plaques. A potencial role in acute plaque disruption. Stroke 2000, 3 I:40-47.

II. Jander S, Sitzer M, Schumann R, Schroeter M, Siebler M, Steinmetz H, Stoll G: Inflammation in high-grade carotid stenosis. A possible role for macrophages and $T$ cells in plaque destabilization. Stroke 1998, 29:1625-1630.

12. Rothwell PM, Villagra R, Gibson R, Donders RC, Warlow CP: Evidence of a chronic systemic cause of instability of atherosclerotic plaques. Lancet 355(9197): 19-24. 2000 Jan ।

13. Stoll G, Bendszus M: Inflammation and atherosclerosis. Novel insights into plaque formation and destabilization. Stroke 2006, 37:1923-1932.

14. Redgrave JNE, Lovett JK, Gallagher PJ, Rothwell PM: Histological assessment of $\mathbf{5 2 6}$ symptomatic carotid plaques in relation to the nature and timing of ischemic symptoms. The Oxford plaque study. Circulation 2006, I I 3:2320-2328.

I5. Nighoghossian N, Derex L, Douek P: The vulnerable carotid artery plaque. Current imaging methods and new perspectives. Stroke 2005, 36:2764-2772.

16. Geroulakos G, Ramaswami G, Nicolaides A, James K, Labropoulos N, Belcaro G, Holloway M: Characterization of symptomatic and asymptomatic carotid plaques using high-resolution realtime ultrasonography. Br J Surg 1993, 80: I 274- I 277.

17. Nandalur KR, Baskurt E, Hagspiel KD, Phillips CD, Kramer CM: Calcified carotid atherosclerotic plaque is associated lesswith ischemic symptoms than is noncalcified plaque on MDCT. AJR 2005, I 84:295-298.

18. Mathiesen $\mathrm{EB}$, Bonaa $\mathrm{KH}$, Joakimsen $\mathrm{O}$ : Echolucent plaques are associated with high risk of ischemic cerebrovascular events in carotid stenosis: the tromso study. Circulation 2001, | 03:2 |7|-2175.

19. Gronholdt MLM, Nordestgaard BG, Schroeder TV, Vorstrup S Sillesen $\mathrm{H}$ : Ultrasonic echolucent carotid plaques predict future strokes. Circulatio 200I, 104:68-73.

20. Tegos TJ, Stavropoulos P, Sabetai MM, Khodabakhsh P, Sassano A, Nicolaides AN: Determinants of carotid plaque instability: echoicity versus heterogeneity. Eur J Vasc Endovasc Surg 200I, 22:22-30.

21. Sabetai MM, Tegos TJ, Nicolaides AN, El-Atrozy TS, Dhanjil S, Griffin M, Belcaro G, Geroulakos G: Hemispheric symptoms and carotid plaque echomorphology. J Vasc Surg 2000, 3 I:39-49.

22. Pedro LM, Pedro MM, Gonçalves I, Carneiro TF, Balsinha C, Fernandes e Fernandes R, Fernandes e Fernandes J: Computer -assisted carotid plaque analysis: characteristics of plaques associated withcerebrovascular symptoms and cerebral infarction. Eur J Vasc Endovasc Surg 2000, I 9: I I8-123.

23. Liapis CD, Kakisis JD, Kostakis AG: Carotid stenosis. Factors affecting symptomatology. Stroke 200I, 32:2782-2786.

24. Tegos TJ, Sohail M, Sabetai MM, Robless P, Akbar N, Pare G, Stansby G, Nicolaides AN: Echomorphologic and histopathologiccharacteristics of unstable carotid plaques. Am J Neuroradiol 2000 , 2 I: 1937-1944.

25. Mazzone AM, Urbani MP, Picano E, Paterni M, Borgatti E, DeFabritiis $A$, Landini $L$ : In vivo ultrasonic parametric imaging of carotid atherosclerotic plaque by videodensitometric technique. Angiology 1995, 46:663-672. 
26. Beletsky VY, Kelley RE, Fowler M, Phifer T: Ultrasound densitometric analysis of carotid plaque composition. Stroke 1996, 27:2173-2177.

27. Aly S, Bishop CC: An objective characterization ofatherosclerotic lesion. An alternative method to identify unstable plaque. Stroke 2000, 31:1921-1924.

28. Lal BK, Hobson RW II, Pappas PJ, Kubicka R, Hameed M, Chakhtura EY, Jamil Z, Padberg FT Jr, Haser PB, Duran WN: Pixel distribution analysis of B - mode ultrasound scan images predicts histologic features of atherosclerotic carotid plaques. J Vasc Surg 2002, 35: $1210-1217$.

29. Sztajel R, Momjian S, Momjian-Mayor I, Murith N, Djebaili K, Boissar G, Comelli M, Pizolato G: Stratified gray-scale median analysis and color mapping of the carotid plaque. Correlation with endarterectomy specimen histology of 28 patients. Stroke 2005, 36:742-745.

Publish with Bio Med Central and every scientist can read your work free of charge

"BioMed Central will be the most significant development for disseminating the results of biomedical research in our lifetime. "

Sir Paul Nurse, Cancer Research UK

Your research papers will be:

- available free of charge to the entire biomedical community

- peer reviewed and published immediately upon acceptance

- cited in PubMed and archived on PubMed Central

- yours - you keep the copyright

Submit your manuscript here:

http://www.biomedcentral.com/info/publishing_adv.asp 